\title{
Reliability assessment of a novel cervical spine deformity classification system
}

\author{
Christopher P. Ames, MD, ${ }^{1}$ Justin S. Smith, MD, PhD, ${ }^{2}$ Robert Eastlack, MD, ${ }^{3}$ \\ Donald J. Blaskiewicz, MD, ${ }^{3}$ Christopher I. Shaffrey, MD, ${ }^{2}$ Frank Schwab, MD, ${ }^{4}$ Shay Bess, MD, ${ }^{5}$ \\ Han Jo Kim, MD, ${ }^{6}$ Gregory M. Mundis Jr., MD, ${ }^{3}$ Eric Klineberg, MD, ${ }^{7}$ Munish Gupta, MD, \\ Michael O'Brien, MD, ${ }^{8}$ Richard Hostin, MD, ${ }^{8}$ Justin K. Scheer, BS, ${ }^{9}$ \\ Themistocles S. Protopsaltis, MD, ${ }^{4}$ Kai-Ming G. Fu, MD, ${ }^{10}$ Robert Hart, MD, ${ }^{11}$ Todd J. Albert, MD, ${ }^{12}$ \\ K. Daniel Riew, MD, ${ }^{13}$ Michael G. Fehlings, MD, PhD, ${ }^{14}$ Vedat Deviren, MD, ${ }^{15}$ Virginie Lafage, PhD, ${ }^{4}$ \\ and the International Spine Study Group
}

${ }^{1}$ Department of Neurosurgery, University of California, San Francisco, California; ${ }^{2}$ Department of Neurosurgery, University of Virginia Medical Center, Charlottesville, Virginia; ${ }^{3}$ San Diego Center for Spinal Disorders, San Diego, California; ${ }^{2}$ Department of Orthopedic Surgery, NYU Hospital for Joint Diseases, New York, New York; ${ }^{5}$ Department of Orthopedic Surgery, Rocky Mountain Hospital for Children, Denver, Colorado; ${ }^{6}$ Department of Orthopedic Surgery, Hospital for Special Surgery, New York, New York; ' Department of Orthopedic Surgery, University of California, Davis, Sacramento, California; ${ }^{8}$ Department of Orthopedic Surgery, Baylor Scoliosis Center, Plano, Texas; ' Department of Neurosurgery, Northwestern University Feinberg School of Medicine, Chicago, Illinois; ${ }^{10}$ Department of Neurosurgery, Weill Cornell Medical College, New York, New York; ${ }^{11}$ Department of Orthopedic Surgery, Oregon Health Sciences University, Portland, Oregon; ${ }^{12}$ Department of Orthopedic Surgery, Thomas Jefferson University, Philadelphia, Pennsylvania; ${ }^{13}$ Department of Orthopedic Surgery, Washington University, St Louis, Missouri; ${ }^{14}$ Department of Neurosurgery, University of Toronto, Ontario, Canada; and ${ }^{15}$ Department of Orthopaedic Surgery, University of California, San Francisco, California

OBJECT Despite the complexity of cervical spine deformity (CSD) and its significant impact on patient quality of life, there exists no comprehensive classification system. The objective of this study was to develop a novel classification system based on a modified Delphi approach and to characterize the intra- and interobserver reliability of this classification.

METHODS Based on an extensive literature review and a modified Delphi approach with an expert panel, a CSD classification system was generated. The classification system included a deformity descriptor and 5 modifiers that incorporated sagittal, regional, and global spinopelvic alignment and neurological status. The descriptors included: "C," "CT," and "T" for primary cervical kyphotic deformities with an apex in the cervical spine, cervicothoracic junction, or thoracic spine, respectively; "S" for primary coronal deformity with a coronal Cobb angle $\geq 15^{\circ}$; and "CVJ" for primary craniovertebral junction deformity. The modifiers included C2-7 sagittal vertical axis (SVA), horizontal gaze (chin-brow to vertical angle [CBVA]), T1 slope (TS) minus C2-7 lordosis (TS-CL), myelopathy (modified Japanese Orthopaedic Association [mJOA] scale score), and the Scoliosis Research Society (SRS)-Schwab classification for thoracolumbar deformity. Application of the classification system requires the following: 1) full-length standing posteroanterior (PA) and lateral spine radiographs that include the cervical spine and femoral heads; 2) standing PA and lateral cervical spine radiographs; 3 ) completed and scored mJOA questionnaire; and 4) a clinical photograph or radiograph that includes the skull for measurement of the CBVA. A series of 10 CSD cases, broadly representative of the classification system, were selected and sufficient radiographic and clinical history to enable classification were assembled. A panel of spinal deformity surgeons was queried to classify each case twice, with a minimum of 1 intervening week. Inter- and intrarater reliability measures were based on calculations of Fleiss $\kappa$ coefficient values.

RESULTS Twenty spinal deformity surgeons participated in this study. Interrater reliability (Fleiss $\kappa$ coefficients) for the deformity descriptor rounds 1 and 2 were 0.489 and 0.280 , respectively, and mean intrarater reliability was 0.584 .

ABBREVIATIONS $\mathrm{CBVA}=$ chin-brow to vertical angle; $\mathrm{CL}=$ cervical lordosis; $\mathrm{CSD}=$ cervical spine deformity; $\mathrm{CVJ}=$ craniovertebral junction; $\mathrm{HRQOL}=$ health-related quality of life; LL = lumbar lordosis; mJOA = modified Japanese Orthopaedic Association Scale; NDI = Neck Disability Index; SF-36 = 36-Item Short Form Health Survey; PA = posteroanterior; PI = pelvic incidence; PT = pelvic tilt; SRS = Scoliosis Research Society; SVA = sagittal vertical axis; TS = T-1 slope.

SUBMITTED August 2, 2014. ACCEPTED December 30, 2014.

INCLUDE WHEN CITING Published online August 14, 2015; DOI: 10.3171/2014.12.SPINE14780. 
For the modifiers, including the SRS-Schwab components, the interrater (round 1/round 2) and intrarater reliabilities (Fleiss $\kappa$ coefficients) were: C2-7 SVA $(0.338 / 0.412,0.584)$, horizontal gaze $(0.779 / 0.430,0.768)$, TS-CL $(0.721 / 0.567$, $0.720)$, myelopathy $(0.602 / 0.477,0.746)$, SRS-Schwab curve type $(0.590 / 0.433,0.564)$, pelvic incidence-lumbar lordosis $(0.554 / 0.386,0.826)$, pelvic tilt $(0.714 / 0.627,0.633)$, and C7-S1 SVA $(0.071 / 0.064,0.233)$, respectively. The parameter with the poorest reliability was the C7-S1 SVA, which may have resulted from differences in interpretation of positive and negative measurements.

CONCLUSIONS The proposed classification provides a mechanism to assess CSD within the framework of global spinopelvic malalignment and clinically relevant parameters. The intra- and interobserver reliabilities suggest moderate agreement and serve as the basis for subsequent improvement and study of the proposed classification.

http://thejns.org/doi/abs/10.3171/2014.12.SPINE14780

KEY WORDS cervical spine deformity; classification; horizontal gaze; kyphosis; validation; myelopathy; sagittal alignment

$\mathrm{D}$ ESPITE the complexity of cervical spine deformity (CSD) and its substantial impact on patient quality of life, there exists no comprehensive classification system to serve as the basis of communication among physicians and to facilitate effective clinical and radiographic study of patients with these deformities. Without a standardized classification system, studies of CSD may suffer from heterogeneity, which compromises the study findings and negatively impacts communication of the results. Other spinal conditions, including adult and pediatric thoracolumbar deformity, spondylolisthesis, and trauma, have benefitted substantially from standardized classification systems. ${ }^{26,30,31,40,44,55}$ An established and validated classification system for CSD could prove fundamentally valuable to future study of CSD.

Beyond the simple grouping of various deformity patterns, a clinically useful CSD classification should also serve as a guide for patient management and a foundation for evidence-based care. ${ }^{32,44,48}$ Substantial progress has been made toward development of such a classification for adult thoracolumbar deformity. This process began using a modified Delphi approach in which established surgeons in the field of thoracolumbar deformity surgery created a classification framework based primarily on expert opinion and available literature. The classification evolved through an iterative process as the literature matured with regard to the most clinically impactful radiographic parameters. ${ }^{3,15,32,38-41,43}$ Ultimately, this process culminated in the merging of efforts of the Scoliosis Research Society (SRS) and of Schwab and colleagues to produce a widely accepted classification. ${ }^{40}$ The resulting SRS-Schwab classification has been validated ${ }^{40}$ and demonstrated to correlate with standardized health-related quality of life (HRQOL) measures ${ }^{40,44,55}$ and to be meaningfully responsive to changes in disease state. ${ }^{44}$

In contrast to adult thoracolumbar deformity, there is currently a limited understanding of the most important clinical and radiographic parameters for patients with CSD, and no reported efforts to develop a CSD classification. Early progress has demonstrated correlations between cervical positive sagittal malalignment and HRQOL (36-Item Short Form Health Survey [SF36] physical component score and Neck Disability Index [NDI],${ }^{54}$ between cervical positive sagittal malalignment and myelopathy (modified Japanese Orthopaedic Association [mJOA] scale score) ${ }^{45}$ and between the occurrence of thoracolumbar and cervical deformities ${ }^{46,49}$ In addition, Ames et al. recently reported a standardized nomenclature for cervical spine soft-tissue release and osteotomy for deformity correction. ${ }^{4}$ The proposed nomenclature includes 7 anatomical grades of increased extent of bone/soft tissue resection and destabilization, as well as a surgical approach modifier. A reliability analysis demonstrated that this system is consistent and directly applicable. ${ }^{4}$

As an initial step toward the long-term goal of developing a comprehensive classification for CSD, our objectives in the present study were to propose and validate an initial classification system for CSD that will have utility in reporting of treatment options and outcomes for affected patients.

\section{Methods}

\section{Development and Description of Classification System}

As a first step toward the development of a comprehensive CSD classification, an extensive review of the literature was conducted and published on cervical spine alignment, sagittal deformity, and clinical implications. ${ }^{37}$ In the context of this background information, a panel of experienced cervical spine surgeons was convened, and based on a modified Delphi approach, an initial CSD classification was generated. ${ }^{6}$ The resulting classification consisted of a deformity descriptor and 5 modifiers (Fig. 1).

For the purposes of this Delphi-based project, experts were defined as those who devote the majority of their practice to adult spinal deformity surgery, including cervical spine and cervical thoracic deformity surgery, and have experience in the use and development of classification systems for clinical practice and research. This is similar to the way in which other Delphi processes have identified their "experts" such as for the Spinal Instability Neoplastic Score for neoplastic disease and others. ${ }^{12}$

\section{Deformity Descriptor}

The descriptor category and specific descriptors were selected to provide a basic grouping of the deformity type (Fig. 1). The first 3 types are primary sagittal deformities that are differentiated by the location of the deformity 
Cervical deformity classification

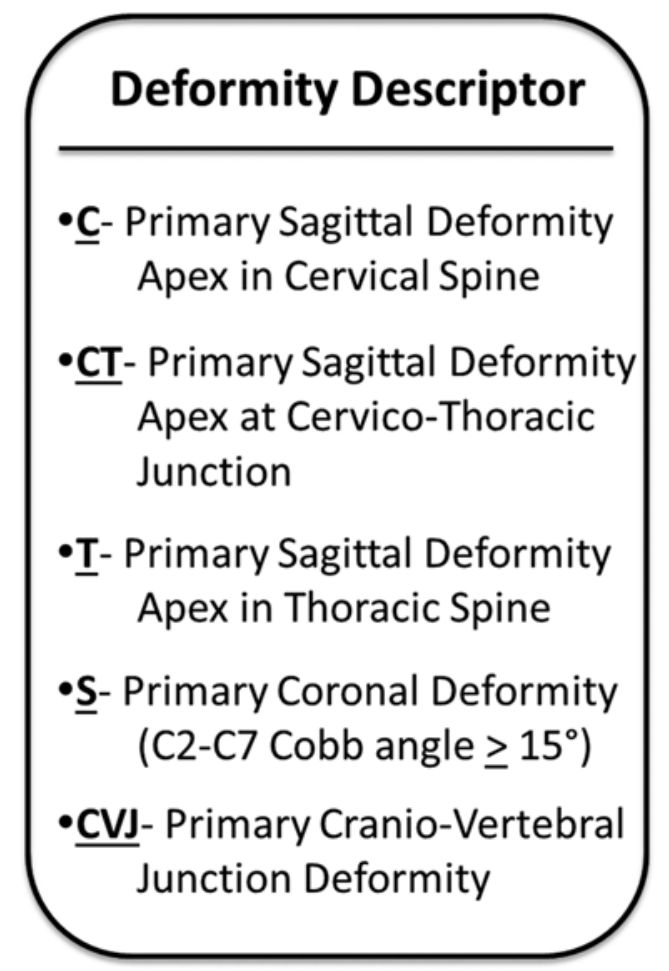

-C2-C7 sagittal vertical axis (SVA)

-0: C2-C7 SVA < $4 \mathrm{~cm}$

1.: C2-C7 SVA $4 \mathrm{~cm}-8 \mathrm{~cm}$

-2: C2-C7 SVA > 8cm

- Horizontal Gaze

-0. CBVA $1^{\circ}-10^{\circ}$

-1: CBVA $-10^{\circ}-0^{\circ}$ or $11^{\circ}-25^{\circ}$

-2: CBVA $<-10^{\circ}$ or $>25^{\circ}$

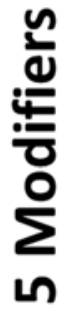

FIG. 1. Description of the CSD classification system, which includes a deformity descriptor and 5 modifiers. $D=$ double; $L=$ lordosis; $\mathrm{N}=$ none; $\mathrm{T}$ = thoracic.

apex, with Type $\mathrm{C}$ for apex in the cervical spine, Type CT for apex at the cervicothoracic junction, and Type $\mathrm{T}$ for apex in the thoracic spine (Fig. 2A-C). Primary coronal deformities are those with a $\mathrm{C} 2-\mathrm{C} 7$ coronal Cobb angle $\geq 15^{\circ}$ and are designated as Type S (Fig. 2D). Type CVJ corresponds to primary craniovertebral junction (CVJ) deformities (Fig. 2E).

\section{C2-7 Sagittal Vertical Axis Modifier}

Common measures of global sagittal spinal alignment include the C2-S1 sagittal vertical axis (SVA) and the C7-S1 SVA, which correspond to the horizontal offsets between the C-2 and C-7 plumb lines, respectively, and the posterosuperior corner of the S-1 vertebral body. ${ }^{3,41}$ Positive global sagittal malalignment has been correlated with standardized measures of pain and disability. ${ }^{13,14,41}$ Translation specifically of the cervical spine in the sagittal plane may also be assessed and multiple measures have been proposed based on the horizontal offsets between the center of gravity of the head, anterior tubercle of $\mathrm{C}-1$, or the centroid of C-2 and the posterosuperior corner of the C-7 vertebral body ${ }^{37}$ Of these, the C2-7 SVA (Fig. 3) has been correlated with multiple measures of HRQOL. Tang and colleagues assessed 113 patients treated with multilevel posterior cervical fusion for cervical stenosis, myelopathy, and/or kyphosis and reported that C2-7 SVA negatively correlated with SF-36 physical component scores and positively correlated with the NDI. ${ }^{54}$ Smith et al. assessed 56 patients with cervical spondylotic myelopathy and reported a significant correlation between C2-7 SVA and mJOA score. ${ }^{45}$

Given the significant impact of sagittal alignment on HRQOL among patients with thoracolumbar spinal deformities, and the studies of Tang et al. ${ }^{54}$ and Smith et al. ${ }^{45}$ demonstrating correlations between cervical sagittal alignment and multiple measures of HRQOL, the C2-7 SVA was selected as a modifier for the CSD classification. Based on regression analysis from Tang et al., a C2-7 SVA threshold of $4 \mathrm{~cm}$ was found to correlate with moderate disability based on the NDI. ${ }^{54}$ Thus, 3 scores were proposed for the C2-7 SVA modifier: 1) a score of "0" corresponding to a C2-7 SVA $<4 \mathrm{~cm}$; 2) a score of "1" corresponding to a C2-7 SVA of 4-8 cm; and 3) a score of "2" corresponding to a C2-7 SVA > $8 \mathrm{~cm}$ (Fig. 1).

\section{Horizontal Gaze Modifier}

The chin-brow to vertical angle (CBVA) is a measure of horizontal gaze. The CBVA is defined as the angle subtended between a line drawn from the patient's chin to brow and a vertical line (Fig. 4). The CBVA is typically measured based on clinical photographs of the patient with hips and knees extended and the neck in a neutral or 

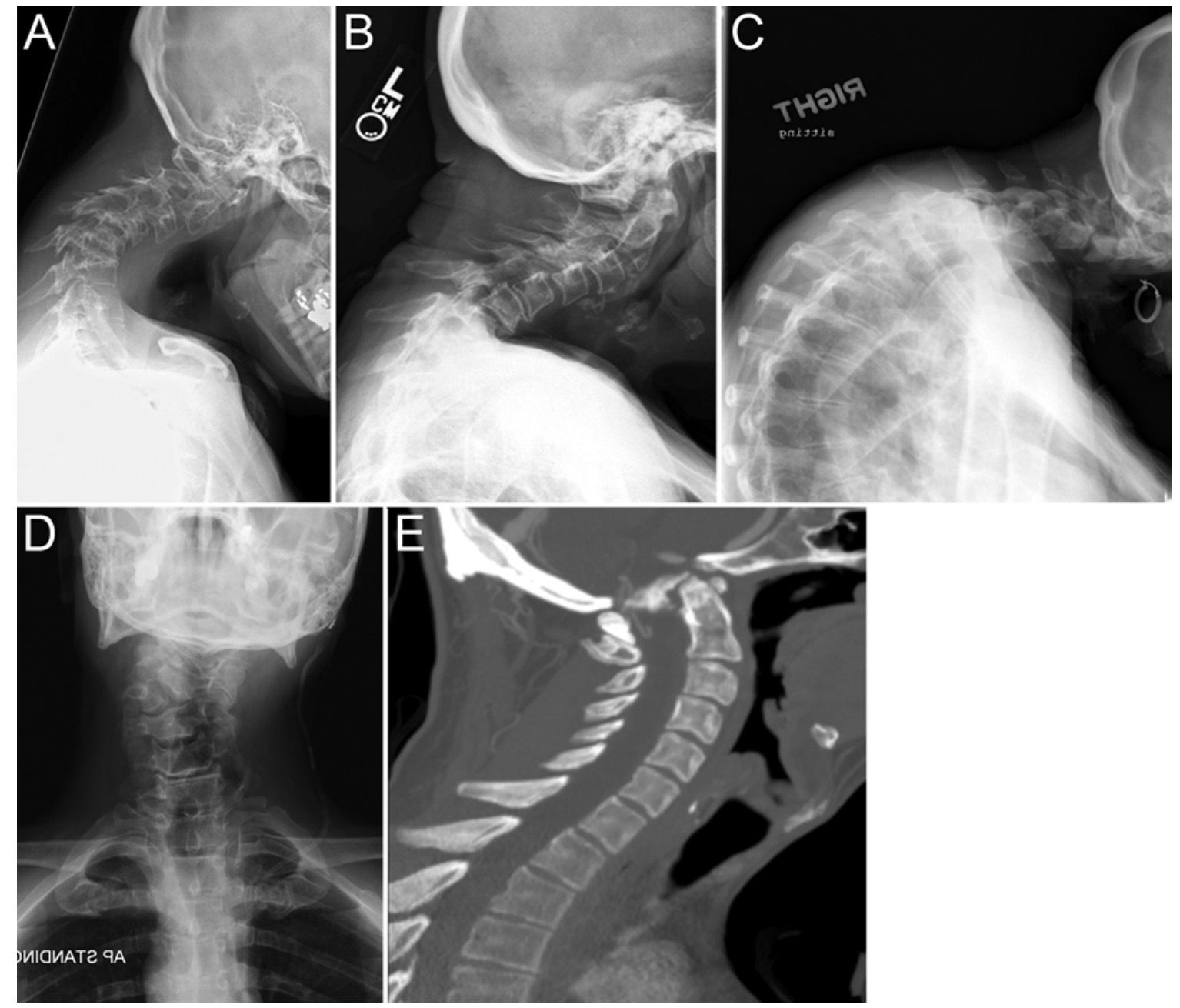

FIG. 2. Case examples illustrating the 5 cervical deformity descriptor types of the proposed CSD classification system. Shown are standing lateral cervical radiographs of a primary sagittal deformity with apex in the cervical spine (Type C, panel A), primary sagittal deformity with apex at the cervicothoracic junction (Type CT, panel B), and primary sagittal deformity with apex in the thoracic spine (Type T, panel C). A standing anteroposterior cervical radiograph shows a cervical scoliosis secondary to a left hemivertebra as an example of a primary coronal deformity (Type S, panel D), and a sagittal CT image shows a case of basilar invagination as an example of a primary CVJ deformity (Type CVJ, panel E).

fixed position. ${ }^{37,52}$ The CBVA may also be assessed based on radiographs that include the skull. With clinical photographs, the CBVA can be readily assessed and consideration of this parameter has been associated with favorable outcomes following correction of spinal deformity, including improved gaze, ambulation, and activities of daily living. $8,9,22,23,36,37,52,58$

Based on the fundamental impact of horizontal gaze on basic human function and previous reports demonstrating the importance of accounting for horizontal gaze in spine deformity surgery, CBVA was selected as a modifier for the CSD classification. Although thresholds of normal CBVA have not yet been rigorously defined, a CBVA of $10^{\circ}$ has been described as an optimal target. ${ }^{37}$ Suk and colleagues reported that overcorrection of CBVA had a negative impact, noting that the 7 patients in their series with CBVA $<-10^{\circ}$ had significantly lower scores for horizontal gaze (especially for going down stairs). ${ }^{52}$ Based on expert opinion, 3 scores were proposed for the horizontal gaze modifier: 1) a score of " 0 " corresponding to a CBVA of $1^{\circ}-10^{\circ} ; 2$ ) a score of " 1 " corresponding to a CBVA of $-10^{\circ}$ to $0^{\circ}$ or $11^{\circ}-25^{\circ}$; and 3 ) a score of " 2 " corresponding to a CBVA of $<-10^{\circ}$ or $>25^{\circ}$ (Fig. 1 ).

\section{T-1 Slope Minus C2-7 Lordosis Modifier}

A significant advancement in the assessment and treatment of thoracolumbar spinal deformity has been the appreciation of the relationship between pelvic morphology and lumbar lordosis (LL). 3,29,35,41,43,51 Although it had been long recognized that normative LL spans a substantial range, perhaps as broad as $30^{\circ}-90^{\circ}$, it was not clear what determined a normal value for an individual. Recent reports have suggested that the morphology of the pelvis, as measured by the pelvic incidence (PI), is a key determinant of ideal LL. ${ }^{3,29,41}$ Individuals with a high PI have a more horizontal sacrum and require a commensurately greater LL. In contrast, individuals with a lower PI have a more vertical sacrum and require less LL. Schwab and 


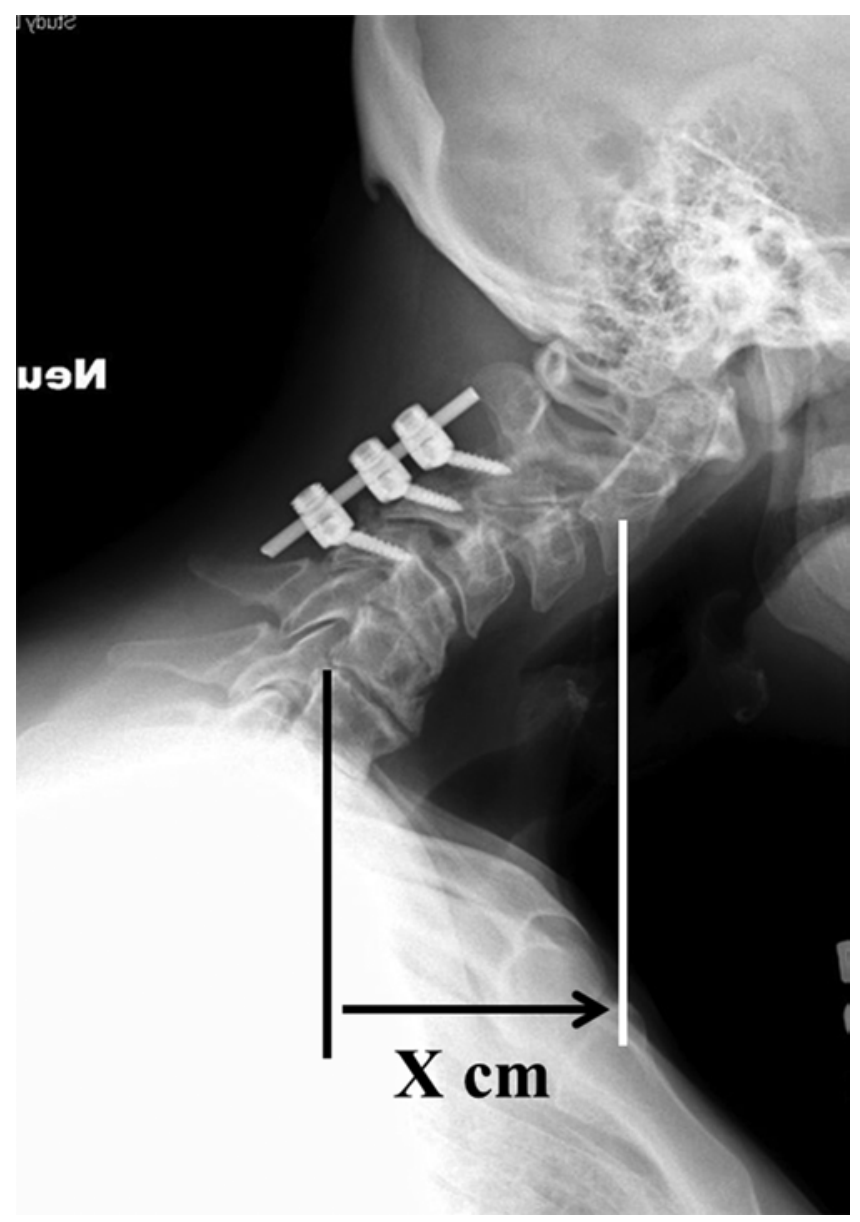

FIG. 3. Example of cervical SVA (C2-7 SVA) measurement. The vertical white line on the lateral radiograph is a plumb line dropped from the center of $\mathrm{C}-2$, and the black vertical line is a plumb line dropped from the posterosuperior corner of the C-7 vertebral body. The horizontal line with an arrow represents the C2-7 SVA. colleagues have suggested that ideal LL for an individual should be within $10^{\circ}$ of the PI (i.e., $\left.\mathrm{LL}=\mathrm{PI} \pm 10^{\circ}\right) .^{40,41} \mathrm{~A}$ PI-LL mismatch of $>10^{\circ}$ has been correlated with significantly poorer HRQOL, including pain and disability, in adults with thoracolumbar deformity. ${ }^{41,47,50}$

The range of normative values for cervical lordosis (CL) has not been fully defined and what constitutes normal CL for an individual is even less well defined. ${ }^{2}$ Of the few available studies, the majority suggest an increase in neck pain in patients with greater cervical kyphosis, whether in the setting of cervical spine trauma or following operative fusion. ${ }^{21,25,34}$ In addition, the presence of abnormal CL has been associated with less postoperative neurological improvement in cases of myelopathy. ${ }^{34}$ However, the extent to which segmental and/or global sagittal cervical alignment correlates with HRQOL remains controversial, as other studies have not consistently demonstrated similar significant correlations. ${ }^{16,19,57}$

Given that cervical kyphosis is the most common type of CSD and that a subset of studies has identified a clinical impact of this kyphosis, a parameter reflective of CL was selected as a modifier for the CSD classification. In deciding on the optimal parameter to include, consideration was given to the relationship between PI and LL. Lee and colleagues reported on the relationship between T-1 slope (TS) and CL. ${ }^{28}$ The relationship between TS and CL is similar to the relationship between PI and LL, in that a greater TS requires a greater magnitude of CL to balance the head over the thoracic inlet and trunk just as a greater PI requires a greater LL for harmonious alignment. ${ }^{28,37}$ The mismatch between TS and CL (TS-CL) has been proposed as an analogous parameter to the mismatch between PI and LL (Fig. 5). ${ }^{54}$ Based on expert opinion, the TS-CL categories selected for the proposed classification were 1) a score of " 0 " corresponding to TS-CL of $<15^{\circ}$; 2) a score of " 1 " corresponding to a TS-CL of $15^{\circ}-20^{\circ}$; and 3) a score of " 2 " corresponding to a TS-CL of $>20^{\circ}$ (Fig. 1).
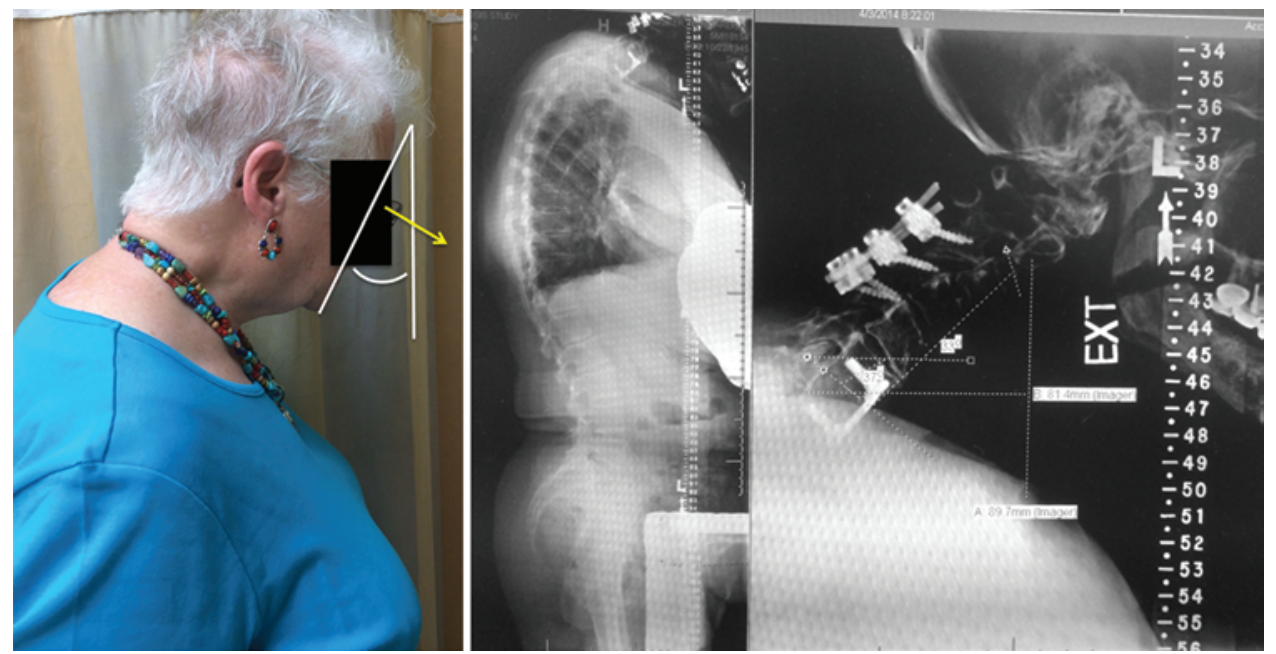

FIG. 4. Example of the CBVA measurement. Shown is a clinical photograph of a patient standing with hips and knees extended while her neck is in a neutral or flexed position (left). The CBVA is defined as the angle subtended between a line drawn from the patient's chin to brow and a vertical reference line. A corresponding full-length standing lateral radiograph and lateral cervical radiograph demonstrate a significantly elevated C2-7 SVA of $9 \mathrm{~cm}$ (right). Figure is available in color online only. 


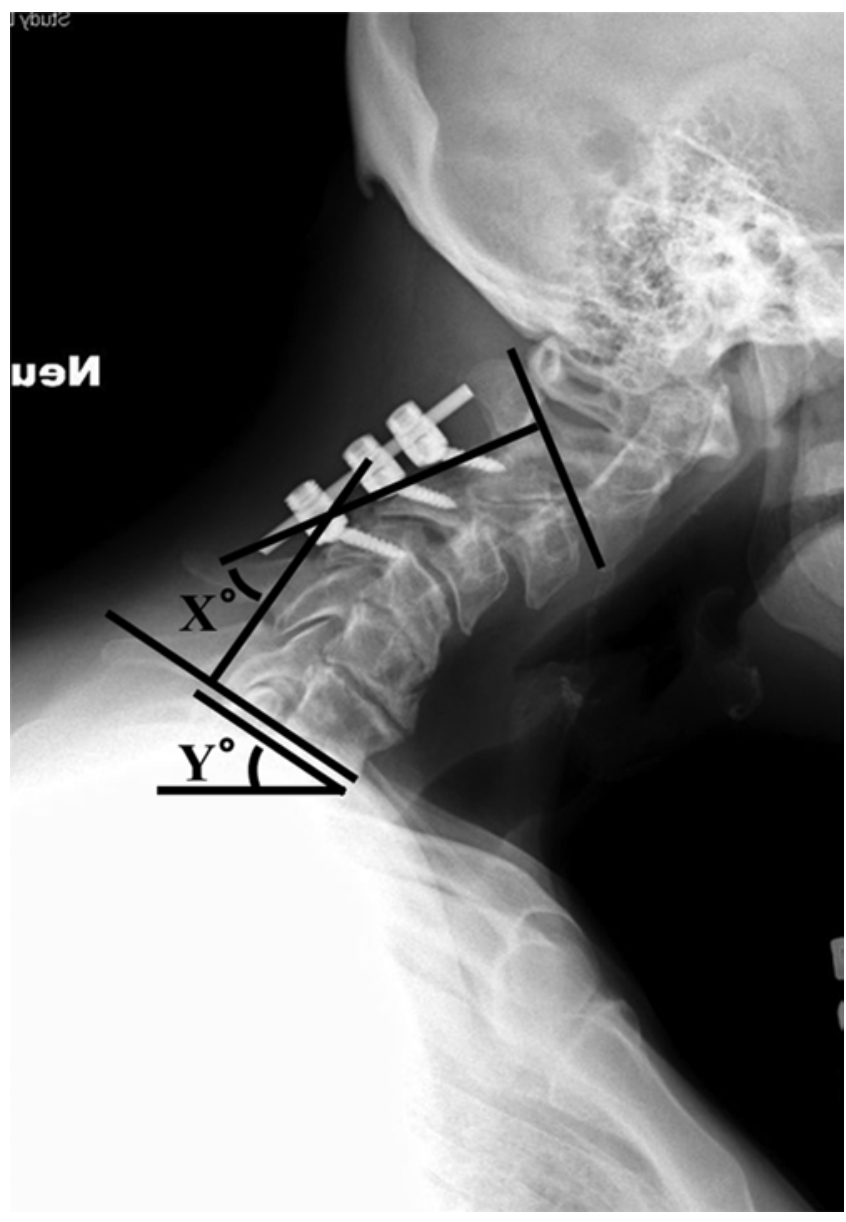

FIG. 5. Example of the TS-CL measurement. Shown is a lateral cervical radiograph. Measurement of the $\mathrm{C} 2-7$ lordosis includes drawing a line parallel to the inferior endplate of $\mathrm{C}-2$ to the posterior margin of the spinous process and another line parallel to the inferior endplate of C-7. Perpendicular lines are then drawn from each of these 2 lines as shown in the radiograph, and the angle subtended between the crossing of the perpendicular lines is the C2-7 lordosis $\left(X^{\circ}\right)$. The TS is the angle subtended by a line drawn parallel to the superior endplate of T-1 and a horizontal reference line $\left(\mathrm{Y}^{\circ}\right)$. TS-CL is calculated as the difference of the 2 measurements.

\section{Myelopathy Modifier}

Cervical myelopathy, the most common cause of spinal cord dysfunction, has traditionally been associated with multilevel spondylosis and direct spinal cord compromise from degenerative changes in the discs, osteophyte formation, and ligamentous and facet hypertrophy. ${ }^{33,56}$ Progressive cervical kyphosis has also been associated with development of myelopathy, through draping and tensioning of the spinal cord over anterior pathology, resulting in direct neural injury and ischemic changes. $1,2,7,18,20,24,42,53$ In addition, a significant correlation between positive sagittal cervical malalignment (C2-7 SVA) and myelopathy severity has been reported.$^{45}$ Thus, patients with CSD may develop myelopathy not only from the direct compression resulting from spondylotic changes, but also due to the deformity itself. Surgical strategies for patients with CSD should address spinal cord compromise when present, which may be through direct decompression, deformity correction, or both.
Because myelopathy can be directly related to CSD and because it can profoundly impact patient function, a measure of myelopathy was selected for inclusion in the CSD classification. The mJOA score is a recognized and widely accepted quantitative functional assessment of the severity of spondylotic myelopathy. ${ }^{5}$ Scores range from 0 to 18 on the mJOA scale, with lower scores reflecting a more severe impact. Based on expert opinion and on categorizations from previously published studies, ${ }^{10,11}$ the mJOA scale categories selected for the proposed classification were 1) a score of " 0 " corresponding to an mJOA scale score of 18 (no myelopathy); 2) a score of "1" corresponding to an mJOA scale score of 15-17 (mild myelopathy); 3) a score of " 2 " corresponding to an mJOA score of 12-14 (moderate myelopathy); and 4) a score of " 3 " corresponding to an mJOA score < 12 (severe myelopathy; Fig. 1).

\section{SRS-Schwab Classification Modifier}

The cervical spine has the widest range of motion relative to the rest of the spine and is the most proximate regulator of alignment of the head and horizontal gaze. As attention has begun to focus on a more global perspective of spinal alignment, it has become increasingly apparent that cervical deformities may contribute to thoracolumbar deformities and thoracolumbar deformities may produce or contribute to cervical deformities. ${ }^{37}$ Ames and colleagues described a significant chain of correlation of sagittal alignment parameters extending from the pelvis (PI) to the lumbar spine, thoracic spine, and cervical spine in a normative population. ${ }^{2}$ In addition, they demonstrated not only a significant correlation between pelvic tilt (PT) and LL, but also a significant direct correlation between PT and CL. ${ }^{2}$ Smith et al. demonstrated that adults with positive sagittal spinopelvic malalignment tend to compensate with abnormally increased CL in an effort to maintain horizontal gaze and that surgical correction of the sagittal malalignment results in improvement of the abnormal cervical hyperlordosis through reciprocal changes. ${ }^{49} \mathrm{Ha}$ and colleagues subsequently confirmed this observation and further identified key radiographic parameters associated with these compensatory changes. ${ }^{17}$ In addition, a high prevalence of concomitant CSD has been reported among adults with thoracolumbar deformity. ${ }^{46}$ Collectively, these and other studies emphasize that assessment and classification of CSD should not occur in isolation and that alignment of the thoracolumbar spine and pelvis should also be assessed. Therefore, the SRS-Schwab classification for adult thoracolumbar spinal deformity was selected as a modifier for the CSD classification. The SRS-Schwab classification includes 5 thoracolumbar coronal curve types and 3 sagittal modifiers (Fig. 6). The SRS-Schwab classification has been validated, shown to correlate with HRQOL measures at baseline, and shown to be sensitive to changes in disease state. ${ }^{40,44,55}$

\section{Classification Reliability}

Based on the proposed CSD classification, a reliability study was conducted using 10 clinical cases that were graded by 20 readers with expertise in CSD patient diagnosis and treatment. Representative cases were selected that had available imaging from a picture archiving and commu- 
nication system that enabled images with minimum 300 dpi, to help control for image quality. The readers were experienced spinal deformity surgeons and the majority of readers were members of a large multicenter spinal deformity study group. Cases were selected to be representative of the classification system descriptors and modifiers. For each case, readers were provided with a sagittal cervical radiograph and full-length standing posteroanterior (PA) and lateral radiographs that included visualization from the occiput to the femoral heads. CBVA and mJOA values were directly provided. The data and imaging provided were intended to simulate a chart review. At a minimum of 1 week following the first reading, the case order was randomized and the cases were resent for repeat grading.

A dedicated MATLAB program (Mathworks) was used to assess interrater and intrarater reliability measures based on calculations of the Fleiss $\kappa$ coefficient values. Kappa values were classified as follows: 0.00-0.20 (slight agreement), 0.21-0.40 (fair agreement), 0.41-0.60 (moderate agreement), 0.61-0.80 (substantial agreement), and $0.81-1.00$ (almost perfect agreement). ${ }^{27}$

\section{Results}

\section{Case Sample}

A series of 10 CSD cases, broadly representative of the proposed CSD classification system, were selected and sufficient radiographic and clinical history to enable classification was assembled. A panel of 20 experienced spinal deformity surgeons was queried to classify each case twice, with a minimum of 1 intervening week. Most assessments were received back for scoring between 7 and 14 days after being sent to the reviewers. An example case is shown in Fig. 7.

\section{Intrarater and Interrater Reliability and Agreement}

Twenty spinal deformity surgeons participated in this study. Interrater reliability (Fleiss $\kappa$ coefficients) for the deformity descriptor rounds 1 and 2 were 0.489 and 0.280 , respectively, and mean intrarater reliability was 0.584 . For the modifiers, including the SRS-Schwab components, the interrater (round 1/round 2) and intrarater reliabilities (Fleiss $\kappa$ coefficients) were C2-7 SVA $(0.338 / 0.412,0.584)$, horizontal gaze $(0.779 / 0.430,0.768)$, TS-CL $(0.721 / 0.567$, 0.720), myelopathy $(0.602 / 0.477,0.746)$, SRS-Schwab classification (curve type [0.590/0.433, 0.564], PI-LL [0.554/0.386, 0.826], PT [0.714/0.627, 0.633], and C7-S1 SVA [0.071/0.064, 0.233]), respectively. Thus, most of the $\kappa$ coefficients for interrater reliability would be classified as reflecting moderate to substantial agreement, with the exceptions of round 1 for C2-7 SVA (fair agreement) and both rounds for the C7-S1 SVA (slight agreement). Most of the $\kappa$ coefficients for the intrarater reliability would also be classified as reflecting moderate to substantial agreement, with the exceptions of PI-LL (almost perfect agreement) and C7-S1 SVA (fair agreement).

\section{Discussion}

Although significant progress has been made with regard to classification and recommended strategies for treat-

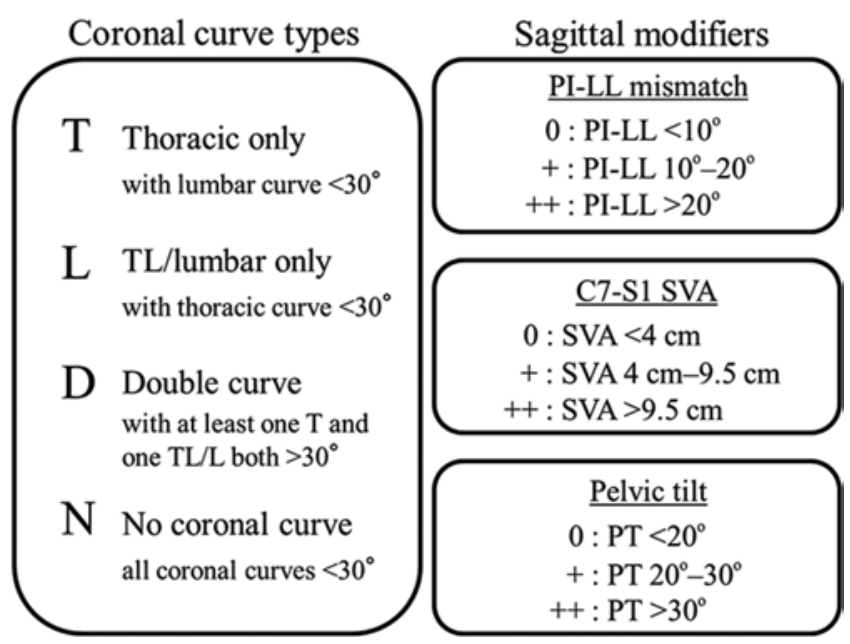

FIG. 6. SRS-Schwab classification system for adult spinal deformity. ${ }^{40}$ The classification consists of 4 coronal curve types and 4 sagittal modifiers. $\mathrm{T}=$ thoracic; $\mathrm{TL}=$ thoracolumbar.

ment of thoracolumbar spinal deformities, corresponding advances have lagged behind for CSDs. One of the initial steps toward formal study of a disease process is the ability to describe and classify the relevant features. For thoracolumbar spinal deformity, achieving a meaningful classification system required multiple iterations that began with an initial classification derived from a modified Delphi approach and expert opinion. The present report reflects an initial attempt to create an effective classification for CSD. The proposed classification includes a basic deformity descriptor and 5 modifiers. Modifiers were selected based on literature review and expert opinion, with a focus on parameters with clinical relevance and impact on patient HRQOL.

Complete application of the classification system requires the following: 1) full-length standing PA and lateral spine radiographs that include the cervical spine and the femoral heads; 2) standing PA and lateral cervical spine radiographs; 3 ) completed and scored $\mathrm{mJOA}$ questionnaire; and 4) a clinical photograph or radiograph that includes the skull for measurement of the CBVA. On the full-length lateral radiograph, visualization of the cervical spine needs to be at least sufficient to visualize the $\mathrm{C}-7$ vertebral body to measure the C7-S1 SVA, and visualization of the femoral heads is necessary for determination of the pelvic parameters. Depending on image quality and the degree to which the cervical spine is visualized, it is typically necessary to also have dedicated cervical spine radiographs for better assessment of the deformity and for measurement of CL and C2-7 SVA. Notably, it is possible that the need for full-length standing radiographs may limit the retrospective application of this classification for many patient cohorts, because there has only been recent recognition of the importance of global imaging of the spine in the setting of CSD.

Most of the proposed classification parameters, including the deformity descriptor and modifiers, had $\kappa$ values reflecting moderate to substantial agreement for both inter- and intrarater reliability. The parameter with the poorest reliability was C7-S1 SVA. Upon further evaluation 


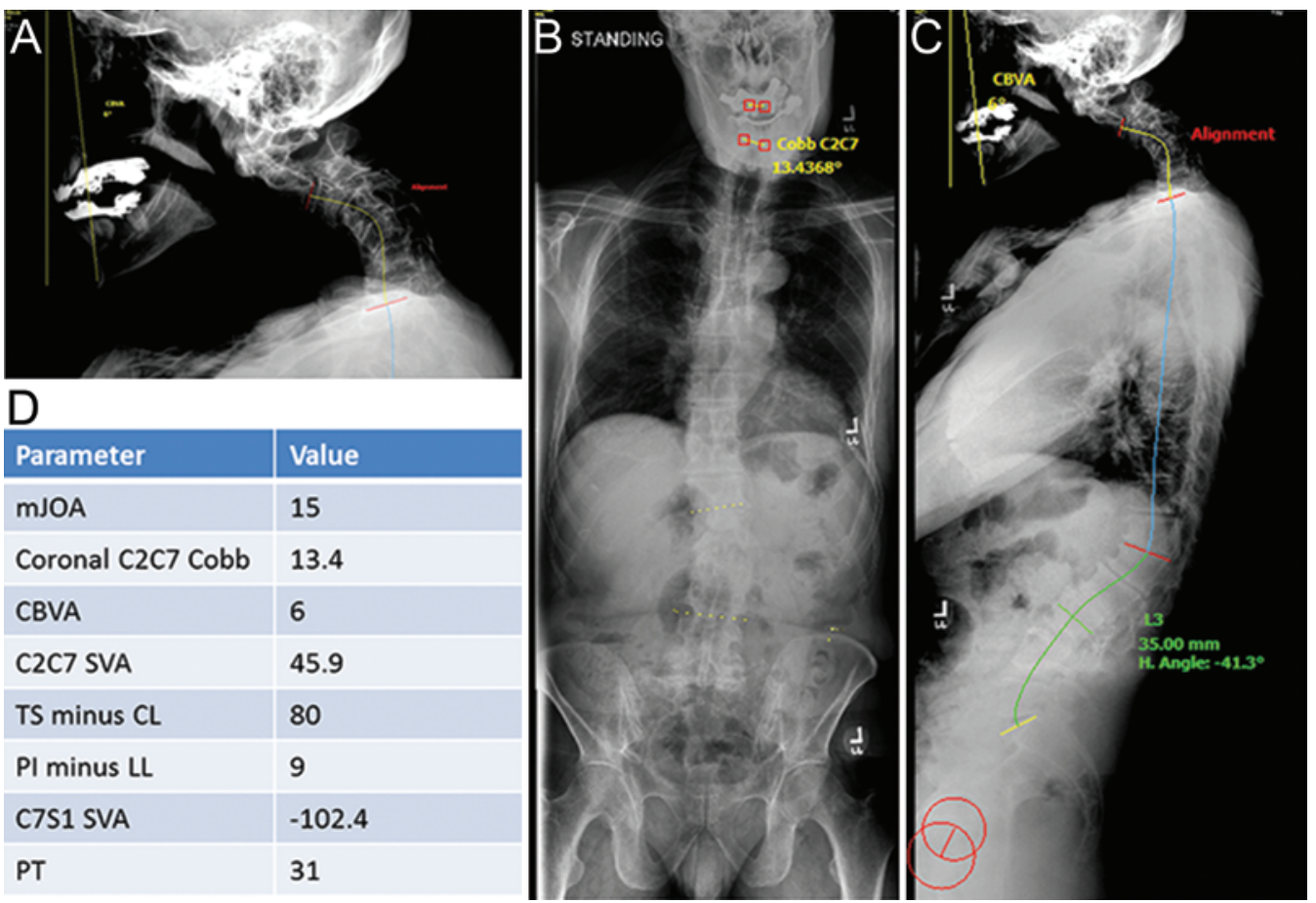

FIG. 7. Case example for validation of the CSD classification system. Images include a lateral cervical spine radiograph (A) and full-length standing PA and lateral radiographs ( $\mathrm{B}$ and $\mathrm{C}$ ). A table of basic radiographic measurements and the mJOA score is also provided (D). This patient would be classified as follows: deformity descriptor " $C$ " (primary sagittal deformity with apex in the cervical spine), C2-7 SVA "1"; horizontal gaze "0"; TS-CL "2"; myelopathy "1"; SRS-Schwab curve type "N," pelvic incidence to lumbar lordosis mismatch "0," C7-S1 SVA "0," and pelvic tilt "++." Figure is available in color online only.

and after querying the reviewers, it became apparent that there were differences in interpretation of how negative values for the C7-S1 SVA should be scored, with several reviewers inconsistently using absolute values. Thus, a C7-S1 SVA of $-9 \mathrm{~cm}$, which should be classified as "0," was inconsistently being classified as "++." In retrospect, additional basic training with regard to classification application could have readily prevented this confusion.

Beyond validating the proposed classification with regard to inter- and intrarater reliability, it will be important to apply the classification to a cohort of patients with CSD at baseline to assess whether the factors presumed to have clinical relevance correlate with objective measures of HRQOL. It will also be important to assess whether changes in the individual modifier grades following surgical treatment are significantly associated with changes in objective measures of HRQOL. Currently, many of the coauthors on the present study are contributing to a prospective multicenter CSD study that is anticipated to serve as a resource for these assessments.

The readers were provided with values for all of the measured parameters, as noted in Fig. 7. It is likely that if the readers had been required to make the measurements themselves there would have been a variance in these values, perhaps resulting in greater inter- and intraobserver variation. However, we believe that as a first step in attempting to delineate and validate a new classification scheme, it would be helpful to eliminate the confounding variability of measurement error. This is a well-accepted methodology in the literature regarding spinal deformity classifications,${ }^{40}$ and none of the individual parameters in the classification are novel or particularly complex, and all have been previously well described in the literature with regard to specific techniques for measurement. ${ }^{37,40,54}$ Notably, despite providing the readers with values for all of the measured parameters, the intra- and interrater reliabilities were not perfect. Similar approaches in which measurements have been provided for validation of a classification have been previously reported and these also have not achieved uniform agreement. ${ }^{40}$

In creating clinically impactful disease classifications, it is important to gain consensus and facilitate refinement through sharing preliminary versions with others actively working in the field. Although we believe our current classification will likely undergo further refinement, many of the parameters we have used have already been shown to have clinical impact (C2-7 SVA, mJOA score, TS-CL, CBVA, and SRS-Schwab classification type). Adoption of this scheme will therefore be useful for increasingly speaking a common language and comparing alternative treatment strategies, outcomes, and complications. As further work is completed, parameters may be added or deleted; this occurred in the development of the SRS-Schwab classification, in which publication and critical analysis of the classification was very useful in its subsequent refinement to its final form.

The present study is not without limitations. The primary limitation relates to the relative lack of high-quality studies in the literature to guide selection of clinically relevant classification parameters. Notably, this is a similar starting point faced by those who created a similar classification for adult thoracolumbar spinal deformity. It is 
possible that, despite an extensive literature search and use of an expert panel, important parameters were missed, and that included parameters may not prove to be useful for classification. In addition, the iterative doubling of the modifier range categories was based on experience with the SRS-Schwab modifiers, in which modifier doubling continued to result in significant sensitivity to health state improvement, ${ }^{44,55}$ while not resulting in excessive numbers of possible individual combinatorial classification states. Although we concede that it is certainly possible that the modifiers and modifier thresholds may need to be refined, disseminating the working scheme will enable such independent assessment and validation by other groups and through other databases. It is expected that the proposed classification system will likely undergo future revision as the present version is applied and additional progress is made toward understanding the critical factors in evaluating and managing these complex spinal deformities.

\section{Conclusions}

The proposed classification system provides a mechanism to assess CSD within the framework of global spinopelvic malalignment and clinically relevant parameters. The intra- and interobserver reliabilities suggest moderate agreement and serve as the basis for subsequent improvement and study of the proposed classification.

\section{References}

1. Albert TJ, Vacarro A: Postlaminectomy kyphosis. Spine (Phila Pa 1976) 23:2738-2745, 1998

2. Ames CP, Blondel B, Scheer JK, Schwab FJ, Le Huec JC, Massicotte EM, et al: Cervical radiographical alignment: comprehensive assessment techniques and potential importance in cervical myelopathy. Spine (Phila Pa 1976) 38 (22 Suppl 1):S149-S160, 2013

3. Ames CP, Smith JS, Scheer JK, Bess S, Bederman SS, Deviren $\mathrm{V}$, et al: Impact of spinopelvic alignment on decision making in deformity surgery in adults: A review. J Neurosurg Spine 16:547-564, 2012

4. Ames CP, Smith JS, Scheer JK, Shaffrey CI, Lafage V, Deviren $\mathrm{V}$, et al: A standardized nomenclature for cervical spine soft-tissue release and osteotomy for deformity correction: clinical article. J Neurosurg Spine 19:269-278, 2013

5. Benzel EC, Lancon J, Kesterson L, Hadden T: Cervical laminectomy and dentate ligament section for cervical spondylotic myelopathy. J Spinal Disord 4:286-295, 1991

6. Boulkedid R, Abdoul H, Loustau M, Sibony O, Alberti C: Using and reporting the Delphi method for selecting healthcare quality indicators: a systematic review. PLoS ONE 6:e20476, 2011

7. Deutsch H, Haid RW, Rodts GE, Mummaneni PV: Postlaminectomy cervical deformity. Neurosurg Focus 15(3):E5, 2003

8. Deviren V, Scheer JK, Ames CP: Technique of cervicothoracic junction pedicle subtraction osteotomy for cervical sagittal imbalance: report of 11 cases. J Neurosurg Spine 15(3):174-181, 2011

9. Etame AB, Than KD, Wang AC, La Marca F, Park P: Surgical management of symptomatic cervical or cervicothoracic kyphosis due to ankylosing spondylitis. Spine (Phila Pa 1976) 33:E559-E564, 2008

10. Fehlings MG, Smith JS, Kopjar B, Arnold PM, Yoon ST, Vaccaro AR, et al: Perioperative and delayed complications associated with the surgical treatment of cervical spondylotic myelopathy based on 302 patients from the AOSpine North America Cervical Spondylotic Myelopathy Study. J Neurosurg Spine 16:425-432, 2012

11. Fehlings MG, Wilson JR, Kopjar B, Yoon ST, Arnold PM, Massicotte EM, et al: Efficacy and safety of surgical decompression in patients with cervical spondylotic myelopathy: results of the AOSpine North America prospective multicenter study. J Bone Joint Surg Am 95:1651-1658, 2013

12. Fisher CG, DiPaola CP, Ryken TC, Bilsky MH, Shaffrey CI, Berven SH, et al: A novel classification system for spinal instability in neoplastic disease: an evidence-based approach and expert consensus from the Spine Oncology Study Group. Spine (Phila Pa 1976) 35:E1221-E1229, 2010

13. Glassman SD, Berven S, Bridwell K, Horton W, Dimar JR: Correlation of radiographic parameters and clinical symptoms in adult scoliosis. Spine (Phila Pa 1976) 30:682-688, 2005

14. Glassman SD, Bridwell K, Dimar JR, Horton W, Berven S, Schwab F: The impact of positive sagittal balance in adult spinal deformity. Spine (Phila Pa 1976) 30:2024-2029, 2005

15. Goldstein LA, Waugh TR: Classification and terminology of scoliosis. Clin Orthop Relat Res (93):10-22, 1973

16. Guérin P, Obeid I, Gille O, Bourghli A, Luc S, Pointillart $\mathrm{V}$, et al: Sagittal alignment after single cervical disc arthroplasty. J Spinal Disord Tech 25:10-16, 2012

17. Ha Y, Schwab F, Lafage V, Mundis G, Shaffrey C, Smith J, et al: Reciprocal changes in cervical spine alignment after corrective thoracolumbar deformity surgery. Eur Spine J 23:552-559, 2014

18. Iida H, Tachibana S: Spinal cord intramedullary pressure: direct cord traction test. Neurol Med Chir (Tokyo) 35:75-77, 1995

19. Jagannathan J, Shaffrey CI, Oskouian RJ, Dumont AS, Herrold C, Sansur CA, et al: Radiographic and clinical outcomes following single-level anterior cervical discectomy and allograft fusion without plate placement or cervical collar. J Neurosurg Spine 8:420-428, 2008

20. Jarzem PF, Quance DR, Doyle DJ, Begin LR, Kostuik JP: Spinal cord tissue pressure during spinal cord distraction in dogs. Spine (Phila Pa 1976) 17 (8 Suppl):S227-S234, 1992

21. Jenkins LA, Capen DA, Zigler JE, Nelson RW, Nagelberg S: Cervical spine fusions for trauma. A long-term radiographic and clinical evaluation. Orthop Rev Suppl:13-19, 1994

22. Kim KT, Lee SH, Son ES, Kwack YH, Chun YS, Lee JH: Surgical treatment of "chin-on-pubis" deformity in a patient with ankylosing spondylitis: a case report of consecutive cervical, thoracic, and lumbar corrective osteotomies. Spine (Phila Pa 1976) 37:E1017-E1021, 2012

23. Kim KT, Suk KS, Cho YJ, Hong GP, Park BJ: Clinical outcome results of pedicle subtraction osteotomy in ankylosing spondylitis with kyphotic deformity. Spine (Phila Pa 1976) 27:612-618, 2002

24. Kitahara Y, Iida H, Tachibana S: Effect of spinal cord stretching due to head flexion on intramedullary pressure. Neurol Med Chir (Tokyo) 35:285-288, 1995

25. Kwon B, Kim DH, Marvin A, Jenis LG: Outcomes following anterior cervical discectomy and fusion: the role of interbody disc height, angulation, and spinous process distance. J Spinal Disord Tech 18:304-308, 2005

26. Labelle H, Mac-Thiong JM, Roussouly P: Spino-pelvic sagittal balance of spondylolisthesis: a review and classification. Eur Spine J 20 (Suppl 5):641-646, 2011

27. Landis JR, Koch GG: The measurement of observer agreement for categorical data. Biometrics 33:159-174, 1977

28. Lee SH, Kim KT, Seo EM, Suk KS, Kwack YH, Son ES: The influence of thoracic inlet alignment on the craniocervical sagittal balance in asymptomatic adults. J Spinal Disord Tech 25:E41-E47, 2012 
29. Legaye J, Duval-Beaupère G, Hecquet J, Marty C: Pelvic incidence: a fundamental pelvic parameter for three-dimensional regulation of spinal sagittal curves. Eur Spine J 7:99-103, 1998

30. Lenke LG, Betz RR, Haher TR, Lapp MA, Merola AA, Harms J, et al: Multisurgeon assessment of surgical decisionmaking in adolescent idiopathic scoliosis: curve classification, operative approach, and fusion levels. Spine (Phila Pa 1976) 26:2347-2353, 2001

31. Lenke LG, Betz RR, Harms J, Bridwell KH, Clements DH, Lowe TG, et al: Adolescent idiopathic scoliosis: a new classification to determine extent of spinal arthrodesis. J Bone Joint Surg Am 83-A:1169-1181, 2001

32. Lowe T, Berven SH, Schwab FJ, Bridwell KH: The SRS classification for adult spinal deformity: building on the King/ Moe and Lenke classification systems. Spine (Phila Pa 1976) 31 (19 Suppl):S119-S125, 2006

33. Matz PG, Anderson PA, Holly LT, Groff MW, Heary RF, Kaiser MG, et al: The natural history of cervical spondylotic myelopathy. J Neurosurg Spine 11:104-111, 2009

34. Naderi S, Ozgen S, Pamir MN, Ozek MM, Erzen C: Cervical spondylotic myelopathy: surgical results and factors affecting prognosis. Neurosurgery 43:43-50, 1998

35. Oh JK, Smith JS, Shaffrey CI, Lafage V, Schwab F, Ames CP, et al: Sagittal spinopelvic malalignment in Parkinson disease: prevalence and associations with disease severity. Spine (Phila Pa 1976) 39:E833-E841, 2014

36. Pigge RR, Scheerder FJ, Smit TH, Mullender MG, van Royen BJ: Effectiveness of preoperative planning in the restoration of balance and view in ankylosing spondylitis. Neurosurg Focus 24(1):E7, 2008

37. Scheer JK, Tang JA, Smith JS, Acosta FL Jr, Protopsaltis TS, Blondel B, et al: Cervical spine alignment, sagittal deformity, and clinical implications: a review. J Neurosurg Spine 19:141-159, 2013

38. Schwab F, el-Fegoun AB, Gamez L, Goodman H, Farcy JP: A lumbar classification of scoliosis in the adult patient: preliminary approach. Spine (Phila Pa 1976) 30:1670-1673, 2005

39. Schwab F, Farcy JP, Bridwell K, Berven S, Glassman S, Harrast J, et al: A clinical impact classification of scoliosis in the adult. Spine (Phila Pa 1976) 31:2109-2114, 2006

40. Schwab F, Ungar B, Blondel B, Buchowski J, Coe J, Deinlein D, et al: Scoliosis Research Society-Schwab adult spinal deformity classification: a validation study. Spine (Phila Pa 1976) 37:1077-1082, 2012

41. Schwab FJ, Blondel B, Bess S, Hostin R, Shaffrey CI, Smith JS, et al: Radiographical spinopelvic parameters and disability in the setting of adult spinal deformity: a prospective multicenter analysis. Spine (Phila Pa 1976) 38:E803-E812, 2013

42. Shimizu K, Nakamura M, Nishikawa Y, Hijikata S, Chiba K, Toyama Y: Spinal kyphosis causes demyelination and neuronal loss in the spinal cord: a new model of kyphotic deformity using juvenile Japanese small game fowls. Spine (Phila Pa 1976) 30:2388-2392, 2005

43. Smith JS, Bess S, Shaffrey CI, Burton DC, Hart RA, Hostin $\mathrm{R}$, et al: Dynamic changes of the pelvis and spine are key to predicting postoperative sagittal alignment after pedicle subtraction osteotomy: a critical analysis of preoperative planning techniques. Spine (Phila Pa 1976) 37:845-853, 2012

44. Smith JS, Klineberg E, Schwab F, Shaffrey CI, Moal B, Ames CP, et al: Change in classification grade by the SRSSchwab Adult Spinal Deformity Classification predicts impact on health-related quality of life measures: prospective analysis of operative and nonoperative treatment. Spine (Phila Pa 1976) 38:1663-1671, 2013

45. Smith JS, Lafage V, Ryan DJ, Shaffrey CI, Schwab FJ, Patel AA, et al: Association of myelopathy scores with cervical sagittal balance and normalized spinal cord volume: analysis of 56 preoperative cases from the AOSpine North America Myelopathy study. Spine (Phila Pa 1976) 38 (22 Suppl 1):S161-S170, 2013

46. Smith JS, Lafage V, Schwab FJ, Shaffrey CI, Protopsaltis T, Klineberg E, et al: Prevalence and type of cervical deformity among 470 adults with thoracolumbar deformity. Spine (Phila Pa 1976) 39:E1001-E1009, 2014

47. Smith JS, Shaffrey CI, Fu KM, Scheer JK, Bess S, Lafage V, et al: Clinical and radiographic evaluation of the adult spinal deformity patient. Neurosurg Clin N Am 24:143-156, 2013

48. Smith JS, Shaffrey CI, Kuntz C IV, Mummaneni PV: Classification systems for adolescent and adult scoliosis. Neurosurgery 63 (3 Suppl): 16-24, 2008

49. Smith JS, Shaffrey CI, Lafage V, Blondel B, Schwab F, Hostin R, et al: Spontaneous improvement of cervical alignment after correction of global sagittal balance following pedicle subtraction osteotomy. J Neurosurg Spine 17:300-307, 2012

50. Smith JS, Singh M, Klineberg E, Shaffrey CI, Lafage V, Schwab FJ, et al: Surgical treatment of pathological loss of lumbar lordosis (flatback) in patients with normal sagittal vertical axis achieves similar clinical improvement as surgical treatment of elevated sagittal vertical axis: clinical article. J Neurosurg Spine 21:160-170, 2014

51. Sparrey CJ, Bailey JF, Safaee M, Clark AJ, Lafage V, Schwab F, et al: Etiology of lumbar lordosis and its pathophysiology: a review of the evolution of lumbar lordosis, and the mechanics and biology of lumbar degeneration. Neurosurg Focus 36(5):E1, 2014

52. Suk KS, Kim KT, Lee SH, Kim JM: Significance of chinbrow vertical angle in correction of kyphotic deformity of ankylosing spondylitis patients. Spine (Phila Pa 1976) 28:2001-2005, 2003

53. Tachibana S, Kitahara Y, Iida H, Yada K: Spinal cord intramedullary pressure. A possible factor in syrinx growth. Spine (Phila Pa 1976) 19:2174-2179, 1994

54. Tang JA, Scheer JK, Smith JS, Deviren V, Bess S, Hart R, et al: Positive cervical sagittal alignment negatively impacts outcomes following adult posterior cervical fusion procedures. Neurosurgery 71:662-669, 2012

55. Terran J, Schwab F, Shaffrey CI, Smith JS, Devos P, Ames $\mathrm{CP}$, et al: The SRS-Schwab adult spinal deformity classification: assessment and clinical correlations based on a prospective operative and nonoperative cohort. Neurosurgery 73:559-568, 2013

56. Tracy JA, Bartleson JD: Cervical spondylotic myelopathy. Neurologist 16:176-187, 2010

57. Villavicencio AT, Babuska JM, Ashton A, Busch E, Roeca C, Nelson EL, et al: Prospective, randomized, double-blind clinical study evaluating the correlation of clinical outcomes and cervical sagittal alignment. Neurosurgery 68:1309-1316, 2011

58. Wang Y, Zhang Y, Mao K, Zhang X, Wang Z, Zheng G, et al: Transpedicular bivertebrae wedge osteotomy and discectomy in lumbar spine for severe ankylosing spondylitis. J Spinal Disord Tech 23:186-191, 2010

\section{Disclosure}

Dr. Ames serves as a consultant to DePuy, Medtronic, and Stryker; has direct stock ownership in Doctors Research Group and Baxano Surgical; is a patent holder for Fish \& Richardson, P.C.; and has received royalties from Aesculap and Biomet Spine. Dr. Smith serves as a consultant to Biomet, NuVasive, DePuy, Medtronic, and Cerapedics; has received clinical or research support for this study from DePuy/ISSG; and has also received support of non-study-related clinical or research effort from DePuy/ISSG. Dr. Eastlack has served as a consultant to Aesculap, 
Alphatec, Depuy Synthes, DiFusion, Invuity, NuVasive, Stryker, $\mathrm{K} 2 \mathrm{M}$, Ulrich, and Carevature; has direct stock ownership in Alphatec and NuVasive; is a patent holder for Invuity, NuTech, and Globus; serves on the speaker's bureau of Eli Lilly; received clinical or research support for this study from Pioneer/RTI and $\mathrm{NuVasive}$; and received statistical analysis for study/writing or editorial assistance on this paper from NuVasive. Dr. Blaskiewicz serves as a consultant to NuVasive. Dr. Shaffrey serves as a consultant to Biomet, Globus, Medtronic, NuVasive, and Stryker; has direct stock ownership in NuVasive; is a patent holder for Biomet, Medtronic, and NuVasive; and has also received royalties from Biomet, Medtronic, and NuVasive. Dr. Schwab has direct stock ownership in, and is an employee of, Nemaris Inc.; has received support of non-study-related clinical or research effort overseen by the author from DePuy, MSD, and AO; is a patent holder for MSD, Nemaris, K2M, and NuVasive; serves as a consultant to MSD, K2M, Medicrea, and DePuy; and has served as a speaker/teacher for MSD, Nemaris Inc., and K2M. Dr. Bess serves as a consultant to K2 Medical and NuVasive. Dr. Mundis $\mathrm{Jr}$ serves as a consultant to NuVasive, K2M, Medicrea, and Misonix; has received clinical or research support for this study from ISSGF; has received support of non-study-related clinical or research effort overseen by the author from NuVasive; and is a patent holder for NuVasive. Dr. Klineberg has served as a consultant to DePuy Synthes, and received speakers' fees and a research grant from AO Spine. Dr. Gupta has direct stock ownership in Proctor and Gamble, Johnson and Johnson, Pfizer, and Pioneer; serves as a consultant to DePuy; has ownership in Medtronic, Orthofix, and Medicrea; has received royalties from DePuy; and is Treasurer of FOSA and a Board Member of SRS. Dr. O'Brien serves as a consultant to DePuy Spine; received royalties from DePuy Spine, Osteotech, and Medtronic; and has received clinical or research support for the study from NuVasive, Seeger, DJO, DePuy Spine, and K2M. Dr. Hostin serves as a consultant to DePuy Spine; and received clinical or research support for the study from NuVasive, Seeger, DJO, DePuy Spine, and K2M. Dr. Protopsaltis serves as a consultant to Medicrea, Biomet Spine, and DePuy Synthes Spine; and has received support of non- study-related clinical or research effort overseen by the author from Zimmer Spine. Dr. Fu serves as a consultant to Medtronic and DePuy. Dr. Hart serves as a consultant to DePuy, Globus, and Medtronic; is a patent holder for OHSU; and has received royalties, study grants, and honoraria from Seaspine, DePuy, and ISSG. Dr. Albert is a patent holder for DePuy Synthes and Biomet, and serves as a consultant to DePuy Synthes. Dr. Riew has served a Board Member for CSRS, Global Spine Journal, and AOSpine International; served on speakers' bureaus for AOSpine, New England Spine Society Group, and NASS; received travel expenses from AOSpine, NASS, SRS, Broadwater, and Selby Spine; received royalties from Biomet, Medtronic, and Osprey; and has direct stock ownership in Amedica, Benvenue, Expanding Orthopedics, Nexgen Spine, Osprey, Paradigm Spine, Spinal Kinetics, Spineology, Vertiflex, and PSD. Dr. Deviren serves as a consultant to NuVasive, Stryker, and Guidepoint. Dr. Lafage has direct stock ownership in Nemaris Inc.; has received support of non-study-related clinical or research effort overseen by the author from DePuy, SRS, NIH, and ISSG; is an employee of Nemaris Inc.; and has served as a speaker/teacher for K2M, DePuy, NuVasive, and Medicrea. The International Spine Study Group (ISSG) is funded through research grants from DePuySynthes and individual donations.

\section{Author Contributions}

Conception and design: Smith, Ames, Eastlack, Protopsaltis, Deviren, Lafage. Acquisition of data: all authors. Analysis and interpretation of data: Smith, Ames, Eastlack. Drafting the article: Smith. Critically revising the article: all authors. Reviewed submitted version of manuscript: all authors. Approved the final version of the manuscript on behalf of all authors: Smith. Statistical analysis: Smith. Administrative/technical/material support: Ames.

\section{Correspondence}

Justin S. Smith, University of Virginia Health Sciences Center, Department of Neurosurgery, PO Box 800212, Charlottesville, VA 22908. e-mail: jss7f@virginia.edu. 